\title{
Mitigating the Effects of Salinity by Foliar Application of Salicylic Acid in Fenugreek
}

\author{
Sumaira Babar, ${ }^{1}$ Ejaz Hussain Siddiqi, ${ }^{1}$ Iqbal Hussain, ${ }^{2}$ \\ Khizar Hayat Bhatti, ${ }^{1}$ and Rizwan Rasheed ${ }^{2}$ \\ ${ }^{1}$ Department of Botany, University of Gujrat, Gujrat 50700, Pakistan \\ ${ }^{2}$ Department of Botany, Government College University, Faisalabad 38000, Pakistan
}

Correspondence should be addressed to Iqbal Hussain; iqbalbotanist1@yahoo.com

Received 6 November 2013; Revised 7 February 2014; Accepted 23 February 2014; Published 1 April 2014

Academic Editor: Vincent Pialoux

Copyright (C) 2014 Sumaira Babar et al. This is an open access article distributed under the Creative Commons Attribution License, which permits unrestricted use, distribution, and reproduction in any medium, provided the original work is properly cited.

Present research work was conducted to alleviate the salinity-induced harmful effect on biomass production and physiochemical attributes of fenugreek by foliar application of salicylic acid. Two varieties (Deli Kabul and Kasuri) were grown in salt treated $(100 \mathrm{mM} \mathrm{NaCl})$ and untreated $(0 \mathrm{mM} \mathrm{NaCl})$ growth medium. Two levels of salicylic acid $\left(0 \mathrm{mg} \mathrm{L}^{-1}\right.$ and $\left.100 \mathrm{mg} \mathrm{L}^{-1}\right)$ were applied through foliar method. Salinity stress significantly reduced the growth biomass in both varieties. Higher shoot fresh weight was recorded in Deli Kabul, while lower in Kasuri. Such reduction in growth biomass was mitigated by the foliar application of SA in both plants. Salinity caused a marked reduction in gas exchange attributes including net $\mathrm{CO}_{2}$ assimilation rate, transpiration rate, stomatal conductance, and substomatal $\mathrm{CO}_{2}$ concentration. Exogenous applied salicylic acid also overcomes the reduction in gas exchange attributes of the plants. The varieties "Deli Kabul" and "Kasuri" showed higher and lower net $\mathrm{CO}_{2}$ assimilation rate, respectively. These results indicate that growth medium salinity induced reduction in biomass production, gas exchange attributes, and also chlorophyll contents whereas the application of SA through foliar method can be used to protect plant growth and improve these attributes under salt stress.

\section{Introduction}

Accumulation of salt whether in soil or water adversely affects various physiological and biochemical processes. For example, reduction in photosynthesis under saline conditions in Safflower [1] and sunflower [2]. Salt-induced reduction in photosynthesis depends on decrease in chlorophyll contents, leaf area, net photosynthetic rate, stomatal conductance, and substomatal $\mathrm{CO}_{2}$ concentrations [3]. Accumulation of salts in the growth medium induces the formation of toxic reactive oxygen species (ROS) including singlet oxygen and superoxide and hydroxyl radical. These reactive oxygen species injured chloroplasts and mitochondria by damaging their cellular structure [4]. To overcome these reactive oxygen species, plants generate antioxidant defense system. Antioxidant defense system produces antioxidant compounds or antioxidant enzymes [5]. It was also suggested that salt tolerance could be promoted by increasing antioxidant defense system in plants.
Salicylic acid is a phenolic compound having ability of antioxidant defense system that regulates various physiological and biochemical processes in plant [6]. Salicylic acid has a key role in tolerance of abiotic stress such as salt tolerance in pea [7], wheat [8], rice [9], sunflower [10], and barley [11] and also in drought tolerance as in wheat [12]. Salicylic acid mitigates harmful effect of drought and salt stress due to its role in photosynthesis [13] and in stomatal regulation [14]. Ghasemzadeh and Jaafar [15] documented while working with sunflower that foliar application of SA enhanced biomass production, photosynthetic pigments, and photosynthetic process. SA also mitigates salt-induced adverse effect in wheat [16]. On the contrary, foliar application of SA inhibits growth and photosynthetic capacity in maize [17]. This alleviation of drought and salt-induced harmful effect depends on type of plant species as well as concentration and mode of application of salicylic acid.

Therefore, an experiment was carried out to determine whether exogenous applied salicylic acid could induce salt 
tolerance in fenugreek plants and to draw relationships between biomass production and net $\mathrm{CO}_{2}$ assimilation rate to illuminate the mechanism which is associated with enhanced salt tolerance in fenugreek due to foliar applied salinity tolerance in fenugreek due to exogenously applied salicylic acid.

\section{Materials and Methods}

2.1. Plant Material, Treatment, and Plant Growth Conditions. Present research work was carried out in Botany Department, University of Gujrat, Pakistan, to alleviate the salt-induced adverse effects on biomass production, photosynthetic pigments, and gas exchange attributes in two varieties of fenugreek by the foliar application of salicylic acid. Seeds of two fenugreek (Trigonella foenum-graecum L.) varieties (Deli Kabul and Kasuri) were obtained from Ayub Agricultural Research Institute (AARI), Faisalabad, Pakistan. Sand was obtained from river Chenab and washed twice with tap water and then with distilled water. Each plastic pot of $25 \mathrm{~cm}$ diameter was filled with $12 \mathrm{~kg}$ sand. Then the seeds of fenugreek were sterilized in 5\% sodium hypochlorite $(\mathrm{NaOCl})$ solution for $5 \mathrm{~min}$ to avoid fungus and other contamination. Ten seeds of each fenugreek variety were sown in each pot with equal depth and distance. After germination, seedlings were thinned to five of equal size. Hoagland nutrient solution was used to each pot. After 15 days of the start of germination salt treatment $(\mathrm{NaCl})$ was applied. Salt treatments were $(0$ as control and $100 \mathrm{mM} \mathrm{NaCl}$ as salt treatment) in full Hoagland nutrient solution. SA treatments were used twice: first time after fifteen days of salt treatment and second time after twenty-five days of salt treatment. Two levels of SA $\left(0\right.$ and $\left.1 \mathrm{mg} \mathrm{L}^{-1}\right)$ with $0.01 \%$ Tween 20 were used to ensure the penetration of SA in the leaf tissues as foliar application at vegetative stage. A constant volume of $5 \mathrm{~mL} /$ plant of the solution (SA) was sprayed with the help of a manual sprayer on all the pots. Arrangement of the experiment was completely randomized design with three replicates. The sampling was done after four weeks of SA treatments.

2.2. Growth Determinations. After harvest, shoot and root fresh and dry weights were recorded. The other plant samples were preserved in cooling chamber at $-20^{\circ} \mathrm{C}$ for determination of physiological and biochemical attributes.

2.3. Gas Exchange Attributes. Measurements of gas exchange parameters such as net photosynthetic rate $(A)$, transpiration $(E)$, substomatal $\mathrm{CO}_{2}$ concentration $\left(C_{i}\right)$, and stomatal conductance $\left(g_{s}\right)$ were measured with an imported LCA-4 ADC open system infrared gas analyzer (IRGA) (Analytical Development Company, Hoddesdon, England). Measurements were performed at $11.00 \mathrm{am}$ in full light intensity with the following specifications/adjustments: molar flow of air per unit leaf area $403.3 \mu \mathrm{mol} \mathrm{m}{ }^{-2} \mathrm{~s}^{-1}$, atmospheric pressure $99.9 \mathrm{kPa}$, water vapor pressure into chamber ranged from 6.0 to 8.9 mbar, PAR at leaf surface was maximum up to 1711 $\mu \mathrm{mol} \mathrm{m} \mathrm{s}^{-2}$, temperature of the leaf ranged from 28.4 to $32.4^{\circ} \mathrm{C}$, ambient temperature ranged from 22.4 to $27.9^{\circ} \mathrm{C}$, and ambient $\mathrm{CO}_{2}$ concentration was $352 \mu \mathrm{mol} \mathrm{mol}{ }^{-1}$.

2.4. Chlorophyll $a$ and $b$ Contents. Chlorophyll $\mathrm{a}$ and $\mathrm{b}$ contents were determined after homogenizing fresh leaves $(0.1 \mathrm{~g})$ in $80 \%$ acetone $(10 \mathrm{~mL})$ and centrifuging at $3000 \times \mathrm{g}$ for $15 \mathrm{~min}$. The absorbance from supernatant was determined at $480 \mathrm{~nm}, 645 \mathrm{~nm}$, and $663 \mathrm{~nm}$ using a spectrophotometer (IRMECO U2020). The amounts of chlorophyll contents were calculated as described by Yoshida et al. [18].

2.5. Statistical Analysis. The experiment was conducted in completely randomized design with three replicates. Data for all variables were subjected to analysis of variance (ANOVA) using a COSTAT computer package (Cohort Software, Berkeley, CA, USA).

\section{Results and Discussion}

Root zone salinity significantly reduced shoot fresh and dry weight of both fenugreek varieties. However, exogenously applied SA significantly enhanced the values of shoot fresh and dry weight in both salt-treated and untreated plants. A clear variation was recorded in both varieties in shoot fresh weight. Higher value of shoot fresh weight was recorded in "Kasuri" while lower in "Deli Kabul". On the contrary, variation in the value of shoot dry weight was nonsignificant. Saline growth medium adversely affects the root fresh and dry weight of both fenugreek varieties. A variable response was recorded in both varieties in root fresh and dry weights. Foliar applied SA enhanced root fresh and dry weight in both salt stressed and nonstressed plants. Less reduction in root fresh and dry weight was recorded in "Deli Kabul" than "Kasuri" (Figure 1).

Salinity in the growth medium caused a significant reduction in the biomass production in the present study. Such salt-induced reduction in growth biomass in fenugreek is in agreement with the earlier findings in wheat [19], maize [20], and rice [21]. Root zone salinity has been shown to reduce the imbibition of water by roots because of decrease in solute potentials of the substrate and creates changes in the metabolism which is responsible for decreasing the plant growth and development. Overall salt-induced decrease in growth biomass may be due to adverse effects on physiological processes such as photosynthesis, ion homeostasis, and accumulation of osmoprotectants. Foliar applied salicylic acid enhanced vegetative growth by increasing fresh and dry biomass. These findings correlate with those of El-Tayeb [11] and Gautam and Singh [22] who documented that foliar applied SA enhanced biomass production in barley and wheat. It is also investigated that the increase in growth biomass in response to SA under salinity stress may be due to protective role of $S A$ on membranes that might be responsible for increasing plant salt tolerance.

Addition of $\mathrm{NaCl}$ to growth medium reduced the value of net $\mathrm{CO}_{2}$ assimilation rate, transpiration rate, stomatal conductance, and substomatal $\mathrm{CO}_{2}$ concentration. Foliar applied 


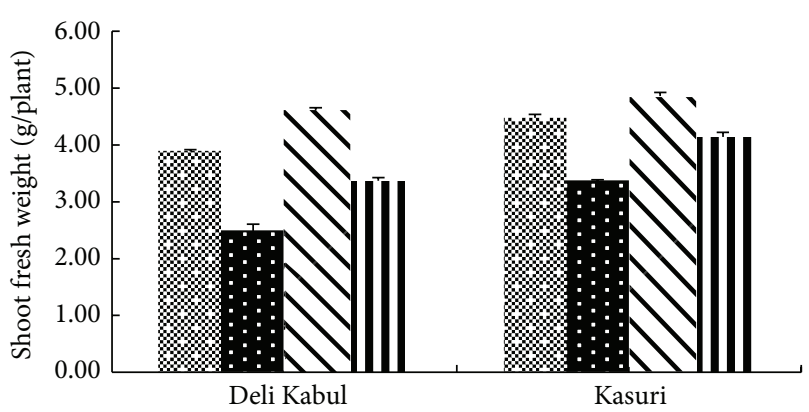

(a)

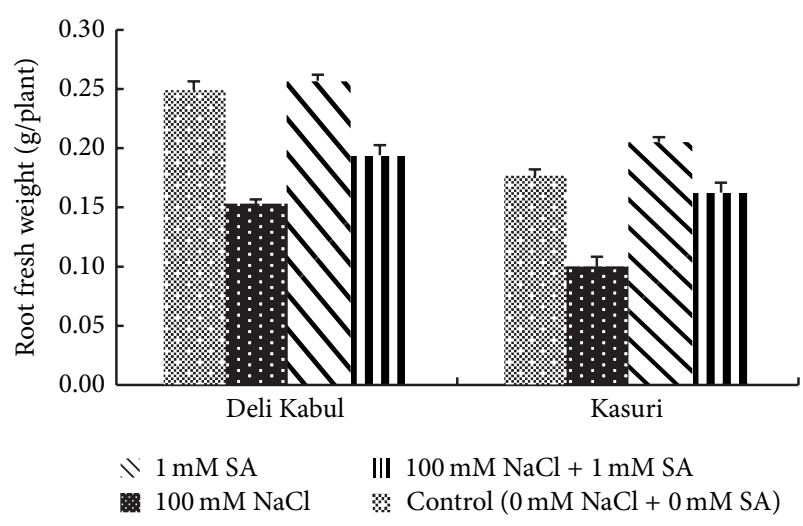

(c)

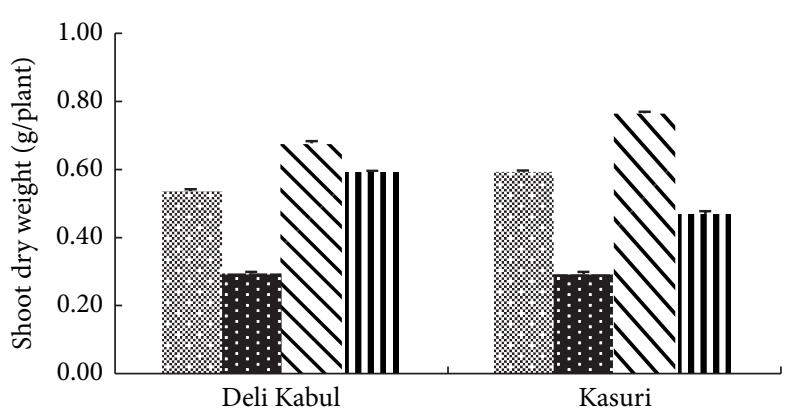

(b)

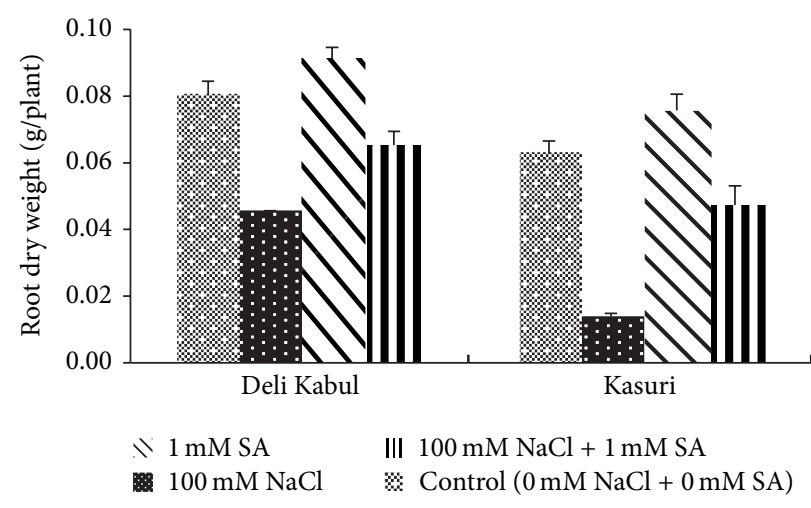

(d)

FIGURE 1: Effect of exogenous application of salicylic acid on biomass production shoot and root fresh and dry weight of two varieties of fenugreek under salt stressed and nonstressed plants.

SA enhanced the values of net $\mathrm{CO}_{2}$ assimilation rate in salttreated and untreated plants. However, "Deli Kabul" showed higher value of net $\mathrm{CO}_{2}$ assimilation rate while "Kasuri" showed lower value both in salt stressed and nonstressed plants. A value of transpiration rate was also improved by foliar applied SA in both varieties in both salt stressed and nonstressed plants. However, variety "Kasuri" showed higher while "Deli Kabul" lower transpiration rate. A clear variation was also found in stomatal conductance in both varieties. The highest value of stomatal conductance was recorded in "Deli Kabul" while the lowest in "Kasuri". Value of substomatal $\mathrm{CO}_{2}$ concentration was also significantly reduced in both varieties due to imposition of root zone salinity. There was no significant difference in both varieties. Values of both varieties are enhanced due to foliar application of SA in salt stressed and nonstressed plants (Figure 2).

Salinity stress decreases growth and development by adversely affecting various physiological and biochemical processes such as photosynthetic capacity, antioxidant activity, and chlorophyll contents [23]. A reduction in plant productivity under saline conditions is related to reduction in photosynthetic capacity via production of reactive oxygen species $[23,24]$. It is documented that root zone salinity creates hindrance in photosynthetic process including photosynthetic pigments, stomatal functioning, gaseous exchange attributes, structure and function of thylakoid membrane, electron transport, and enzyme activities, by hampering the oxidative stress mitigation mechanisms and cellular metabolism of plants [25]. Exogenously applied SA significantly enhanced net photosynthetic rate which could be due to improving the functional state of the photosynthetic machinery in plants either by the mobilization of internal tissue nitrate or by chlorophyll biosynthesis [26]. SA-induced improvement in net $\mathrm{CO}_{2}$ assimilation rate was in agreement with findings of earlier researcher where foliar applied salicylic acid enhanced photosynthetic capacity in various crops, for example, sunflower [2], wheat [16], and soybean [14]. Furthermore, a positive relationship was found between biomass production (shoot fresh weight) and net $\mathrm{CO}_{2}$ assimilation rate which are due to SA-induced changes under saline conditions. Such close relationship between growth biomass production and photosynthetic rate was also found in wheat [16]. In the present study, salinity in the growth medium caused a marked reduction in the transpiration rate, stomatal conductance, and substomatal $\mathrm{CO}_{2}$ concentration. Such saltinduced reduction in these parameters was alleviated by the foliar application of SA. Results of the present study are in agreement with the findings of earlier researcher where salt-induced reduction in these gas exchange attributes was overcome by the foliar application of SA in wheat [27] and sunflower [2].

Growth medium salinity caused a marked reduction in photosynthetic pigments including chlorophyll a and chlorophyll b of both fenugreek varieties (Figure 3). The decrease in 


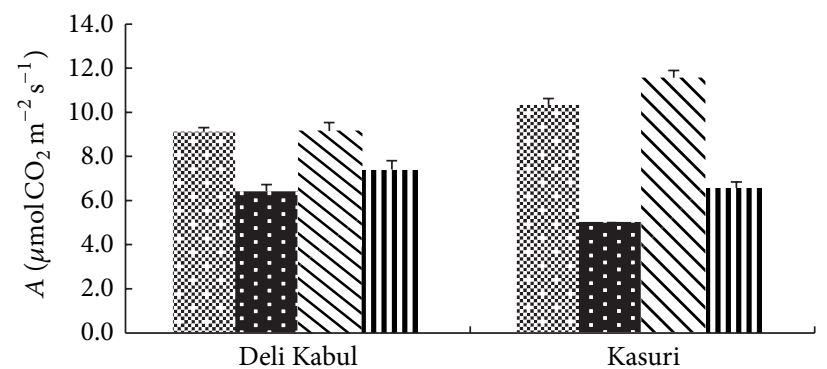

(a)

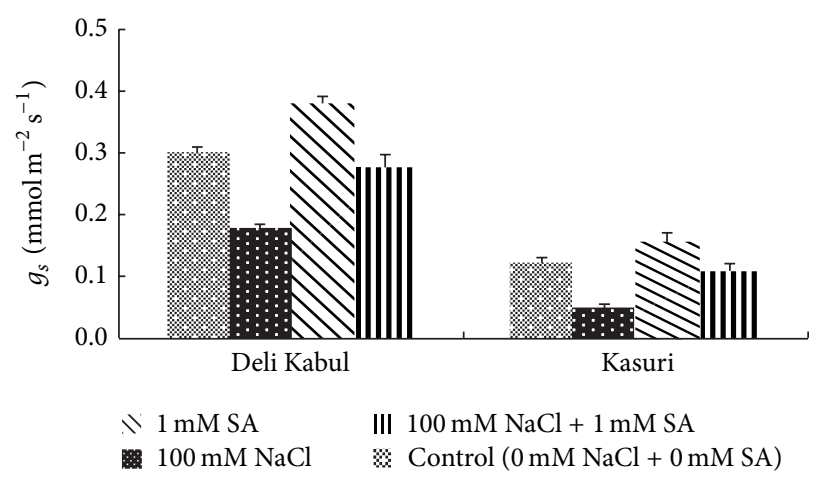

(c)

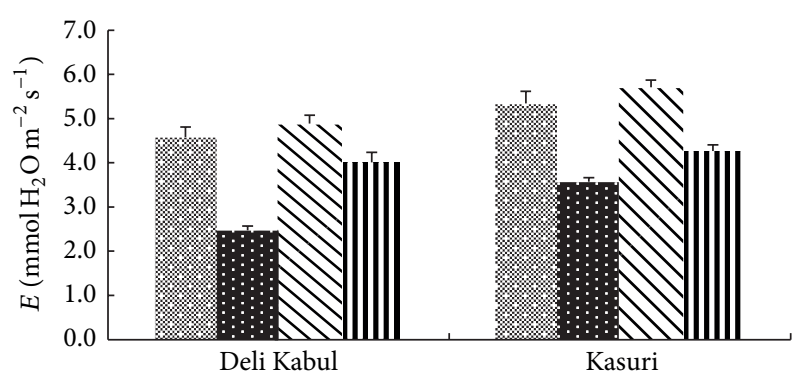

(b)

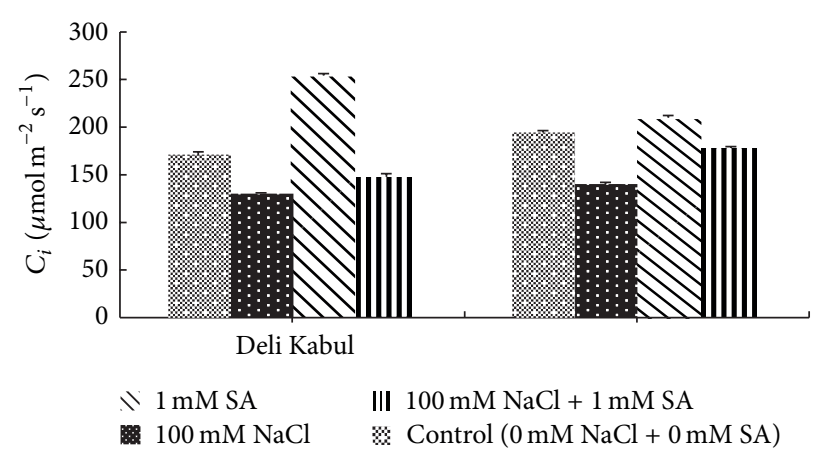

(d)

FIGURE 2: Effect of exogenous application of salicylic acid on gas exchange attributes $\left(A, E, g_{s}\right.$, and $\left.C_{i}\right)$ of two varieties of fenugreek under salt stressed and nonstressed plants.

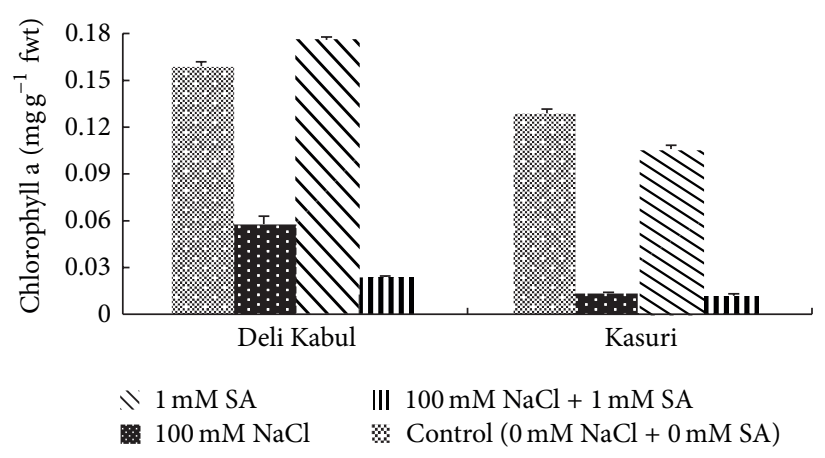

(a)

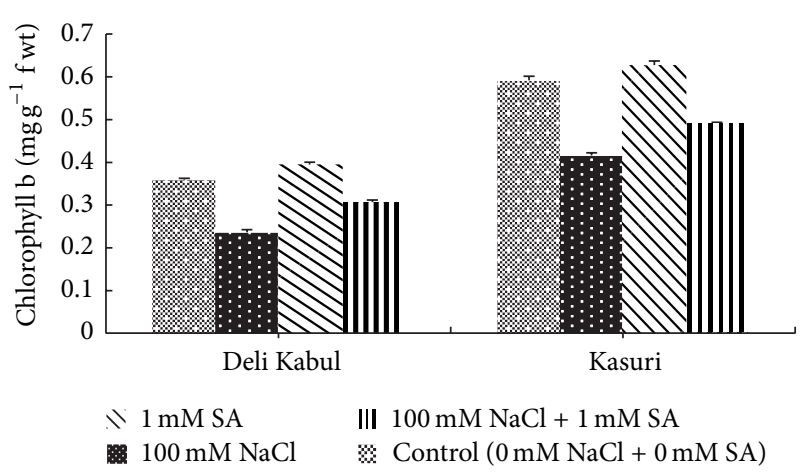

(b)

FIGURE 3: Effect of exogenous application of salicylic acid on chlorophyll a and chlorophyll b contents of two varieties of fenugreek under salt stressed and nonstressed plants.

chlorophyll content in salt-affected fenugreek plants might be attributed to the possible oxidation of chlorophyll and other chloroplast pigments coupled with instability of the pigment protein complex under salt stress [27]. Reduction in these chlorophyll contents was mitigated by the foliar application of SA. Results of the present study are in agreement with the findings of earlier researcher where salt-induced reduction in the chlorophyll contents is alleviated by the foliar application of salicylic acid in crops such as wheat [28], mug bean [29], and tomato [30].

\section{Conclusions}

In conclusion, present study showed that salinity in the growth medium had inhibitory effect on growth of fenugreek plants. Foliar application of SA mitigated the salinity- 
induced adverse effects on the growth biomass, gas exchange attributes, and chlorophyll contents. Therefore, it might be concluded that foliar applied salicylic acid (SA) had stimulatory effects on fenugreek plants under salt stress.

\section{Conflict of Interests}

The authors declare that there is no conflict of interests regarding the publication of this paper.

\section{Authors' Contribution}

Sumaira Babar contributed to collecting the plant sample, running the laboratory work, and analysis and drafting of the data. Iqbal Hussain and Rizwan Rasheed contributed to the analysis of the spectroscopic data and writing of the paper. Ejaz Hussain Siddiqi and Khizar Hayat Bhatti designed the study, supervised the laboratory work, and contributed to critical reading of the paper. All the authors have read the final paper and approved the submission.

\section{Acknowledgment}

The authors are grateful to the Higher Education Commission, Pakistan, for financial support.

\section{References}

[1] E. H. Siddiqi, M. Ashraf, M. Hussain, and A. Jamil, "Assessment of inter-cultivar variation in salt tolerance in safflower using gas exchange characterics as assessment," Pakistan Journal of Botany, vol. 41, no. 5, pp. 2251-2259, 2009.

[2] S. Noreen and M. Ashraf, "Alleviation of adverse effects of salt stress on sunflower (Helianthus annuus L.) by exogenous application of salicylic acid: growth and photosynthesis," Pakistan Journal of Botany, vol. 40, no. 4, pp. 1657-1663, 2008.

[3] P. Sabir, M. Ashraf, M. Hussain, and A. Jamil, "Relationship of photosynthetic pigments and water relations with salt tolerance of proso millet (Panicum Miliaceum L.) accessions," Pakistan Journal of Botany, vol. 41, no. 6, pp. 2957-2964, 2009.

[4] R. Mittler, "Oxidative stress, antioxidants and stress tolerance," Trends in Plant Science, vol. 7, no. 9, pp. 405-410, 2002.

[5] S. S. Gill and N. Tuteja, "Reactive oxygen species and antioxidant machinery in abiotic stress tolerance in crop plants," Plant Physiology and Biochemistry, vol. 48, no. 12, pp. 909-930, 2010.

[6] B. Aberg, "Plant growth regulators XLI. Monosubstituted benzoic acid," Sweden Journal Agricultural Research, vol. 11, pp. 93$105,1981$.

[7] F. Macri, A. Vianello, and S. Pennazio, "Salicylate-collapsed membrane potential in pea stem mitochondria," Physiology Plantarum, vol. 67, pp. 136-140, 1986.

[8] F. M. Shakirova, A. R. Sakhabutdinova, M. V. Bezrukova, R. A. Fatkhutdinova, and D. R. Fatkhutdinova, "Changes in the hormonal status of wheat seedlings induced by salicylic acid and salinity," Plant Science, vol. 164, no. 3, pp. 317-322, 2003.

[9] S. Lutts, J. M. Kinet, and J. Bouharmont, "NaCl-induced senescence in leaves of rice (Oryza sativa L.) cultivars differing in salinity resistance," Annals of Botany, vol. 78, no. 3, pp. 389398, 1996.

[10] S. Noreen, M. Ashraf, M. Hussain, and A. Jamil, "Exogenous application of salicylic acid enhances antioxidative capacity in salt stressed sunflower (Helianthus annuus L.) plants," Pakistan Journal of Botany, vol. 41, no. 1, pp. 473-479, 2009.

[11] M. A. El-Tayeb, "Response of barley grains to the interactive effect of salinity and salicylic acid," Plant Growth Regulation, vol. 45, no. 3, pp. 215-224, 2005.

[12] B. Singh and K. Usha, "Salicylic acid induced physiological and biochemical changes in wheat seedlings under water stress," Plant Growth Regulation, vol. 39, no. 2, pp. 137-141, 2003.

[13] A. M. A. Al-Hakimi, "Alleviation of the adverse effects of $\mathrm{NaCl}$ on gas exchange and growth of wheat plants by ascorbic acid, thiamine and sodium salicylate," Pakistan Journal of Biological Sciences, vol. 4, pp. 762-765, 2001.

[14] W. Khan, B. Prithiviraj, and D. L. Smith, "Photosynthetic responses of corn and soybean to foliar application of salicylates," Journal of Plant Physiology, vol. 160, no. 5, pp. 485-492, 2003.

[15] A. Ghasemzadeh and H. Z. E. Jaafar, "Interactive effect of salicylic acid on some physiological features and antioxidant enzymes activity in ginger (Zingiber officinale Roscoe)," Molecules, vol. 18, pp. 5965-5979, 2013.

[16] M. Arfan, H. R. Athar, and M. Ashraf, "Does exogenous application of salicylic acid through the rooting medium modulate growth and photosynthetic capacity in two differently adapted spring wheat cultivars under salt stress?" Journal of Plant Physiology, vol. 164, no. 6, pp. 685-694, 2007.

[17] M. Németh, T. Janda, E. Horváth, E. Páldi, and G. Szalai, "Exogenous salicylic acid increases polyamine content but may decrease drought tolerance in maize," Plant Science, vol. 162, no. 4, pp. 569-574, 2002.

[18] S. Yoshida, D. A. Forno, J. H. Cock, and K. A. Gomez, Laboratory Manual For Physiological Studies of Rice, IRRI, Los Banos, Calif, USA, 1976.

[19] R. W. Kingsbury and E. Epstein, "Selection for salt-resistant spring wheat," Crop Science, vol. 24, pp. 310-315, 1984.

[20] G. R. Cramer, G. J. Alberico, and C. Schmidt, "Salt tolerance is not associated with the sodium accumulation of two maize hybrids," Australian Journal of Plant Physiology, vol. 21, no. 5, pp. 675-692, 1994.

[21] A. Moons, G. Bauw, E. Prinsen, M. van Montagu, and D. van der Straeten, "Molecular and physiological responses to abscisic acid and salts in roots of salt-sensitive and salt-tolerant Indica rice varieties," Plant Physiology, vol. 107, no. 1, pp. 177-186, 1995.

[22] S. Gautam and P. K. Singh, "Salicylic acid-induced salinity tolerance in corn grown under $\mathrm{NaCl}$ stress," Acta Physiologiae Plantarum, vol. 31, no. 6, pp. 1185-1190, 2009.

[23] M. Ashraf, "Some important physiological selection criteria for salt tolerance in plants," Flora, vol. 199, no. 5, pp. 361-376, 2004.

[24] Z. Noreen, M. Ashraf, and N. A. Akram, "Salt-induced regulation of some key antioxidant enzymes and physio-biochemical phenomena in five diverse cultivars of turnip (Brassica rapa L.)," Journal of Agronomy and Crop Science, vol. 196, no. 4, pp. 273$285,2010$.

[25] P. Sudhir and S. D. S. Murthy, "Effects of salt stress on basic processes of photosynthesis," Photosynthetica, vol. 42, no. 4, pp. 481-486, 2004. 
[26] Q. Shi, Z. Bao, Z. Zhu, Q. Ying, and Q. Qian, "Effects of different treatments of salicylic acid on heat tolerance, chlorophyll fluorescence, and antioxidant enzyme activity in seedlings of Cucumis sativa L," Plant Growth Regulation, vol. 48, no. 2, pp. 127-135, 2006.

[27] P. Stępień and G. Kłbus, "Water relations and photosynthesis in Cucumis sativus L. leaves under salt stress," Biologia Plantarum, vol. 50, no. 4, pp. 610-616, 2006.

[28] S. T. Moharekar, S. D. Lokhande, T. Hara, R. Tanaka, A. Tanaka, and P. D. Chavan, "Effect of salicylic acid on chlorophyll and carotenoid contents of wheat and moong seedlings," Photosynthetica, vol. 41, no. 2, pp. 315-317, 2003.

[29] S. Hayat, Q. Fariduddin, B. Ali, and A. Ahmad, "Effect of salicylic acid on growth and enzyme activities of wheat seedlings," Acta Agronomica Hungarica, vol. 53, no. 4, pp. 433-437, 2005.

[30] S. Zahra, B. Amin, and Y. Mehdi, "The salicylic acid effect on the tomato (Lycopersicum esculentum Mill.) germination, growth and photosynthetic pigment under salinity stress $(\mathrm{NaCl})$, Journal of Stress Physiology and Biochemistry, vol. 6, no. 3, pp. 4-16, 2010. 

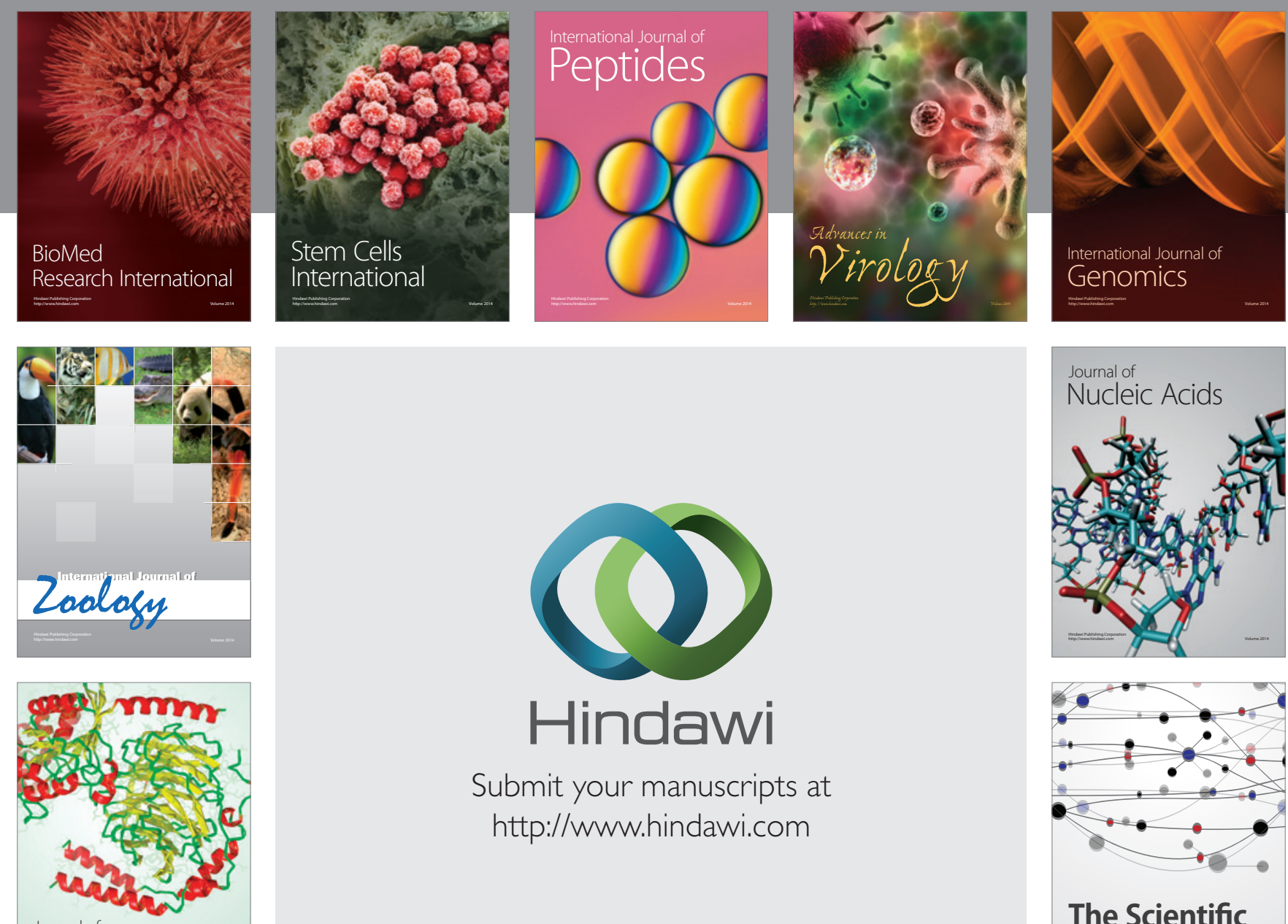

Submit your manuscripts at

http://www.hindawi.com

Journal of
Signal Transduction
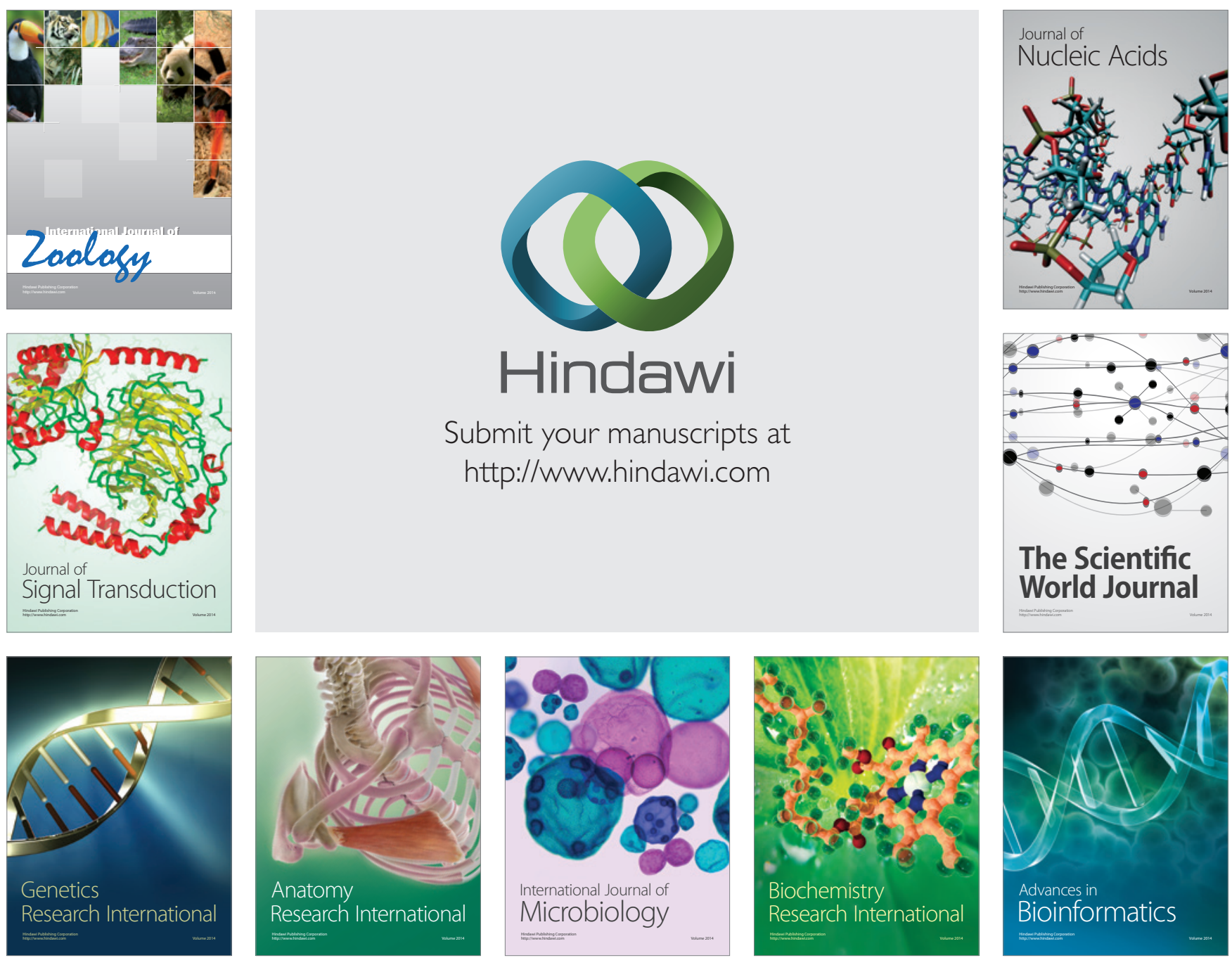

The Scientific World Journal
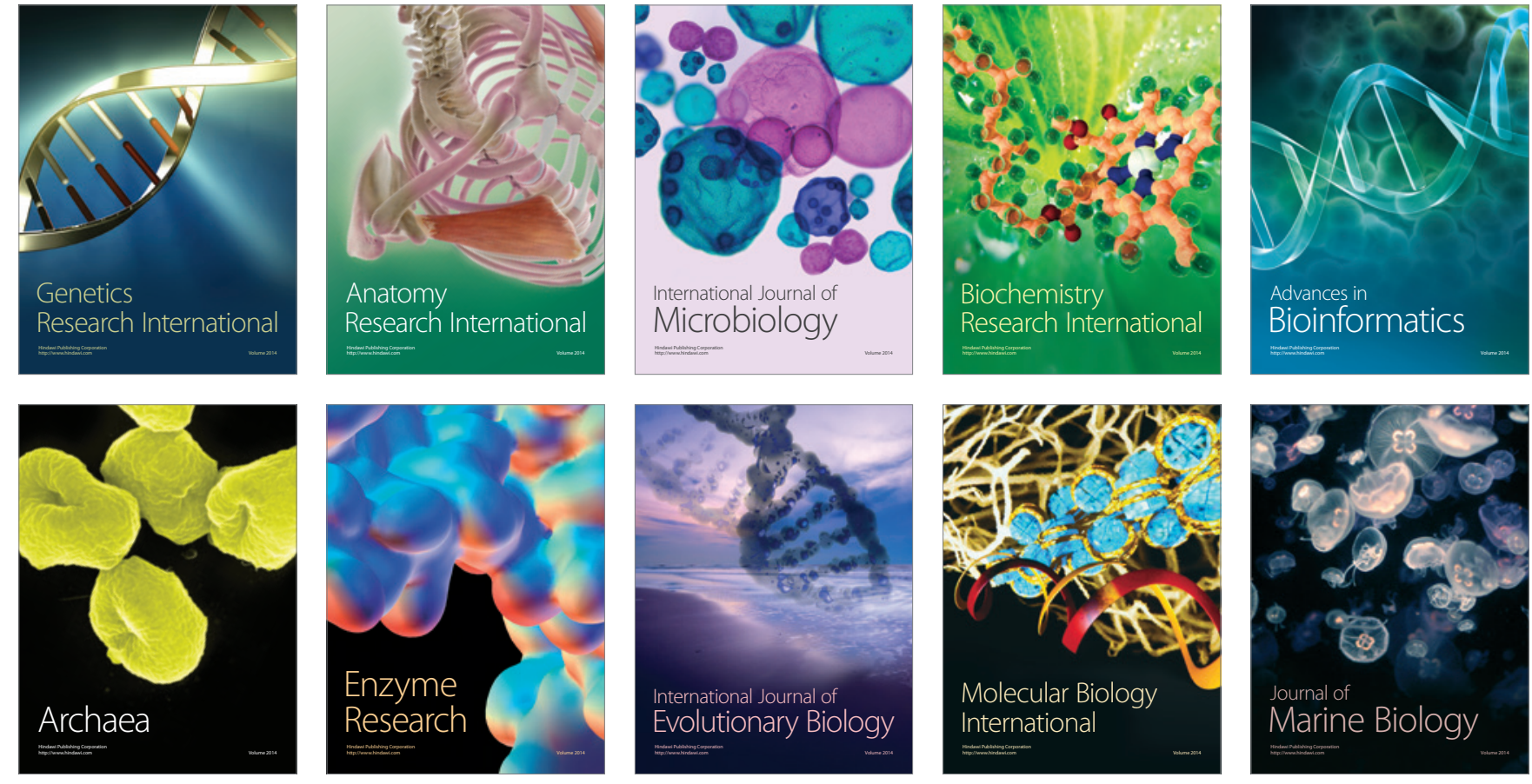